\title{
Collaborative interviewing in mathematical analogy technique (part III): adherence to CBT and duration of treatment Lefteris Konstandinidis*1, Yiota Goga ${ }^{2}$, Thomai Lioura² ${ }^{2}$ and Dimitra Goga ${ }^{3}$
}

Address: ${ }^{1}$ Private Practice, Thessaloniki, Greece, ${ }^{2}$ Association for Mental Health and Social Rehabilitation (Epsica), Thessaloniki, Greece and ${ }^{3} 1$ st State Infant School, Ano-Liosia, Athens, Greece

* Corresponding author

from International Society on Brain and Behaviour: 2nd International Congress on Brain and Behaviour

Thessaloniki, Greece. 17-20 November 2005

Published: 28 February 2006

Annals of General Psychiatry 2006, 5(Suppl I):S75 doi:10.1 186/I744-859X-5-SI-S75

\section{Background}

CLIMATE is an acronym for Collaborative Interviewing in Mathematical Analogy Technique. We developed CLIMATE in order to improve a client's socialization in CBT, to boost his or her motivation for therapy and to recruit his or her best possible collaboration during the therapeutic process.

Although CBT is a short-term highly effective form of psychotherapy, not all patients remain in treatment. Dropout of treatment depends on many factors both demographic and clinical. Realistic (or unrealistic) expectations of therapy as well as the quality of the therapeutic relationship are also significant factors affecting adherence to treatment.

\section{Materials and methods}

Forty-three patients with a variety of DSM-IV diagnoses were dministered CLIMATE just after their intake and evaluation interview (CLIMATE Group, $\mathrm{n}=43$ ). These patients were compared with a control group of fortythree age and gender matched patients with a variety of DSM-IV diagnoses who were not administered CLIMATE (Non-CLIMATE Group, $\mathrm{n}=43$ ).

\section{Results}

Proportionally more clients from the Non-CLIMATE group dropped out of treatment but this difference was not statistically significant. Most clients from the CLIMATE group who dropped-out did so just after the first session while clients from the Non-CLIMATE group who dropped out did so later on (1-5 sessions). There is also a trend toward briefer duration of treatment when CLIMATE is used $(\mathrm{p}=0.079)$.

\section{Discussion}

This finding indicates that CLIMATE helps clients to clarify their expectations of treatment and decide whether they will stay or not in treatment earlier.

\section{References}

I. Blenkiron P: Stories and Analogies in Cognitive Behaviour Therapy: A Clinical Review. Behavioural and Cognitive Psychotherapy 2005, 33:45-49.

2. Tehrani E, Krussel J, Borg L, Munk-Jorgensen P: Dropping out of psychiatric treatment: a prospective study of a first admission cohort. Acta Psychiatry Scand 1996, 94:266-27I.

3. Goga $Y$, Konstadinidis L, Lioura T, Simos G, Nikolaidis N, Gouzaris A: Effective Socialization in CBT: The CLIMATE technique. Poster presentation at the International Congress of Cognitive Psychotherapy Goteborg 2005. 